\title{
Über die Reaktion zwischen Molybdänsäure und einfach- und zweifach-chromsaurem Kalium.
}

\author{
Von \\ ROBERT H. BRADbURY.
}

Nach der Stellung des Molybdäns im periodischen System der Elemente soll es manche Analogieen mit Schwefel und ganz besonders mit Chrom darbieten. So kommt der beständigsten Säure beider die Formel $\mathrm{H}_{2} \mathrm{RO}_{4}$, bezw. $\mathrm{RO}_{3} \mathrm{zu}$; ferner ist es seit einiger Zeit bekannt, dafs Schwefel sowohl wie Chrom ein höheres, unbeständiges Oxyd von der Formel $\mathrm{R}_{2} \mathrm{O}_{7}$ bilden kann, und auch ein hydriertes $\mathrm{Mo}_{2} \mathrm{O}_{7}$ ist vor kurzem dargestellt und untersucht worden.

Zweifach-chromsaures Kali, $\mathrm{K}_{2} \mathrm{Cr}_{2} \mathrm{O}_{7}$, kann auch deutlicher $\mathrm{K}_{2} \mathrm{CrO}_{4} \cdot \mathrm{CrO}_{3}$ geschrieben werden, und wäre dann als 1 Mol. neutralen Chromates, verbunden mit $1 \mathrm{Mol}$. wasserfreier Chromsäure, aufzufassen. Die Existenz von noch höheren wasserfreien chromsauren Salzen, wie z. B. von dreifach-chromsaurem Kali, $\mathrm{K}_{2} \mathrm{Cr}_{3} \mathrm{O}_{10}$, oder $\mathrm{K}_{2} \mathrm{CrO}_{4} \cdot 2 \mathrm{CrO}_{3}$, ist ebenfalls nachgewiesen. Die auffallende Ähnlichkeit zwischen Molybdän und Chrom führte zu der Annahme, dals es vielleicht möglich sein würde, das Chrom in zweifach-chromsaurem Kali durch Molybdän zu ersetzen - d. h. eine Verbindung von der Zusammensetzung $\mathrm{K}_{2} \mathrm{CrO}_{4} \cdot \mathrm{MoO}_{3}$ herzustellen. Da das zweifach-chromsaure Kali durch direkte Addition von wasserfreier Chromsäure zu dem neutralen chromsauren Kali entsteht, so nahmen wir an, dals das hypothetische Chromatmolybdat durch einfache Zugabe von wasserfreier Molybdänsäure $z u$ chromsaurem Kali entstehen würde: $\mathrm{K}_{2} \mathrm{CrO}_{4}+\mathrm{MoO}_{3}=\mathrm{K}_{2} \mathrm{CrO}_{4} \cdot \mathrm{MoO}_{3}$.

Auf den Vorschlag des Herrn Dr. EdGar F. Suith habe ich diese Frage näher untersucht, und obgleich das Resultat nicht unseren Erwartungen entsprach, so ist es doch insofern von Interesse, als es der langen Reihe von Thatsachen eine weitere hinzufügt, welche zeigt, dafs die von einer Substanz in einer Reaktion gespielte Rolle nicht nur von den speziellen Eigenschaften der Substanz, sondern auch in gleichem Grade von der Menge der angewandten Substanz abhängt.

Die Reaktion, welche beim Zusammenbringen von wasserfreier Molybdänsäure mit chromsauren Salzen eintritt, wurde A. mit chromsaurem Kali und B. mit doppelchromsaurem Kali untersucht. 
A. Um die Reaktion von wasserfreier Molybdänsäure auf neutrales chromsaures Kali zu untersuchen, wurde das Salz in Wasser gelöst und eine äquivalente Menge Molybdänsäure in kleinen Portionen hinzugefügt. Sowohl in der kalten wie in der warmen Lösung löst sich die Molybdänsäure schnell auf, während zu gleicher Zeit die Lösung eine tief gelbrote Farbe annimmt; in der Wärme erfolgt die Auflösung schneller. Die Flüssigkeit wurde dann langsam eingedampft, wobei sich zunächst aus der Lösung eine weilse Masse abschied. Dieselbe wurde abfiltriert, getrocknet und untersucht. Sie enthielt kein Chrom und bestand hauptsächlich aus Molybdänsäure, welche vielleicht etwas molybdänsaures Kali enthielt. Das Filtrat, welches seine rötlichgelbe Färbung beibehielt, wurde eingedampft, wobei eine weitere Ausscheidung der weilsen Substanz fortwährend beobachtet wurde. Die letztere wurde von Zeit zu Zeit abfiltriert und das Abdampfen fortgesetzt. Zuletzt erhielten wir ein Filtrat von geringem Volumen, welches anscheinend keine weitere Molybdänsäure enthielt. In diesem Filtrat war die erwähnte rötlichgelbe Färbung viel tiefer, je nach dem Grade der Konzentration, und zeigte, dafs nichts von der färbenden Substanz durch Filtration entfernt war.

Diese Flüssigkeit wurde zur Krystallisation verdunstet und stehen gelassen. Eine Masse von roten Nadeln, welche sich abschied, wurde getrocknet, umkrystallisiert und untersucht. Unter dem Mikroskop unterschied sich das Material nicht von doppeltchromsaurem Kali, - weder durch Krystallform, noch im Verhalten gegen polarisiertes Licht. Die Analyse ergab die Gegenwart einer Spur von Molybdän und setzte die Natur der Substanz aulser Zweifel.

Die Reaktion zwischen wasserfreier Molybdänsäure und chromsaurem Kali vollzieht sich daher nach der folgenden Gleichung: $2 \mathrm{~K}_{2} \mathrm{CrO}_{4}+\mathrm{MoO}_{3}=\mathrm{K}_{2} \mathrm{Cr}_{2} \mathrm{O}_{7}+\mathrm{K}_{2} \mathrm{MoO}_{4}$.

Eine direkte Addition findet nicht statt und eine chrommolybdänsaure Verbindung bildet sich nicht. Aus der Thatsache, dals viel unveränderte wasserfreie Molybdänsäure während des Eindampfens ausgeschieden wurde, und dals die Flüssigkeit einen grofsen Betrag unveränderten chromsauren Kalis enthielt, folgt, dals die Reaktion in keiner Weise quantitativ ist.

In der That ist diese Menge des gebildeten doppeltchromsauren Kalis aufserordentlich klein im Verhältnis zu den angewandten Mengen vox chromsaurem Kali und wasserfreier Molybdänsäure. 
Man sollte in der That - nach der Stellung des Molybdäns in dem periodischen System zu urteilen, nach seinem höheren Atomgewicht und nach allen Eigenschaften seiner Säure, - erwarten, dafs die Avidität der Molybdänsäure bedeutend geringer sei als die der Chromsäure, und dals deshalb die Reaktion: $2 \mathrm{~K}_{2} \mathrm{CrO}_{4}+\mathrm{MoO}_{3}=$ $\mathrm{K}_{2} \mathrm{Cr}_{2} \mathrm{O}_{7}+\mathrm{K}_{2} \mathrm{MoO}_{4}$ nicht weit fortschreiten würde, bevor der $\mathrm{Zu}$ stand des Gleichgewichts erreicht wäre, in welchem die rückgängige Reaktion: $\mathrm{K}_{2} \mathrm{Cr}_{2} \mathrm{O}_{7}+\mathrm{K}_{2} \mathrm{MoO}_{4}=2 \mathrm{~K}_{2} \mathrm{CrO}_{4}+\mathrm{MoO}_{3}$ dieselbe Schnelligkeit erreicht wie die Hauptreaktion, und in welcher daher die Transformation aufhört.

Es wäre vielleicht möglich, die Menge des gebildeten doppeltchromsauren Kalis durch die Erhöhung des Molybdänsäurebetrages zu steigern, bis ein grofser Überschufs davon vorhanden wäre; wir haben jedoch in dieser Richtung keine Versuche unternommen.

B. Trägt man wasserfreie Molybdänsäure in eine Lösung von doppeltchromsaurem Kali ein, und zwar in der Kälte, so scheint kein Wechsel einzutreten, jedoch haben wir, einen oberflächlichen Versuch ausgenommen, keine Versuche in dieser Beziehung angestellt.

Die Reaktion, welche zwischen doppeltchromsaurem Kali und Molybdänsäure beobachtet wurde, findet nur bei höherer Temperatur statt. Äquivalente Mengen von doppeltchromsaurem Kali und wasserfreier Molybdänsäure wurden mit einander gemischt und in einem Porzellantiegel gelinde erwärmt. Das Gemisch schmilzt leicht zu einer schwärzlichbraunen Flüssigkeit zusammen, und zu gleicher Zeit macht sich eine Gasentwickelung, veranlalst durch das Entweichen von Sauerstoff, bemerklich, welche mit steigender Temperatur energischer wird. Als die geschmolzene Masse gleichförmig geworden war, wurde die Wärmezufuhr abgeschnitten. Beim Abkühlen erstarrte die flüssige Masse zu einer brannen Substanz, welche zerkleinert und mit heifsem Wasser behandelt wurde.

Etwas unverändert gebliebenes doppeltchromsaures Kali wurde auf diese Weise entfernt und der unlösliche Rückstand gründlich gewaschen und getrocknet. Er bildet ein weiches, loses Pulver von brauner Farbe und wurde der Analyse unterworfen.

Salzsäure löst den grölsten Teil davon zu einer grünen Lösung, welche Chlor abgiebt. Eine kleine Quantität schwarzen Rückstandes bleibt zurück, welche weder durch Salpetersäure, oder Salpetersäure und chlorsaures Kali, noch durch Schmelzen mit Soda und Schwefel 
angegriffen wird. Der Rückstand wurde daher einfach auf einem gewogenen Filter getrocknet und sein Gewicht von dem der angewandten Substanz abgezogen. Der Weg der Analyse soll kurz beschrieben werden.

Das Material wurde in ein Becherglas eingewogen, genügend starke Salzsäure zugesetzt, um es zu bedecken, und das Glas auf dem Wasserbade erwärmt. Nach vollendeter Zersetzung wurde der stets geringe Rückstand auf ein gewogenes Filter gebracht und sein Gewicht von dem der angewandten Substanz abgezogen. Das grüne Filtrat wurde stark mit Wasser verdünnt und Schwefelwasserstoff lange Zeit eingeleitet. Dreifach-Schwefelmolybdïn $\left(\mathrm{MoS}_{3}\right)$ schlug sich nieder. Es wurde auf ein gewogenes Filter gebracht und sein Gewicht bestimmt. Ein aliquoter Teil des Niederschlages wurde im Roseschen Tiegel in lebhaftem, trockenem Wasserstoffstrom geglïht, um ihn in zweifaches Schwefelmolybdän, $\mathrm{MoS}_{2}$, überzuführen.

Die angewandte Temperatur mufs nicht zu hoch sein, weil sich sonst ein Teil des Materials verflüchtigt, unter Bildung cines schwarzen Sublimats, so dals Verlust entsteht.

Das Zweifach-Schwefelmolybdän wurde damn im Wasserstoffstrom abgekühlt und gewogen, und die dern ganzen Niederschlag und daher der angewandten Substanz entsprechende Molybdänmenge berechnet.

Aus dem Filtrat wurde das Chrom als Hydrat durch Ammoniak gefällt und auf die gewöhnliche Weise als Sesquioxyd berechnet.

Das Kali in dem Filtrate vom Chrom wurde, wie gewöhnlich, als Chlorkalium gewogen.

Es folgen die Resultate:
A
B
C
Durchschnitt:

Mo $43.68 \%$

$43.56 \%$

Cr 14.71,

K 11.08 ,

14.65,

$43.17 \%$

14.78 "

$11.86, \quad 11.47$,

Sauerstoff als Differenz angenommen: 30.29 "

Die Formel $\mathrm{K}_{2} \mathrm{O} . \mathrm{Cr}_{2} \mathrm{O}_{3} .3 \mathrm{MoO}_{3}$ verlangt folgende Zusammensetzung:

$$
\begin{array}{ll}
\text { Mo } & 42.42 \% \\
\text { Cr } & 15.44 " \\
\text { K } & 11.51 " \\
\text { O } & 30.63 "
\end{array}
$$

Die Verbindung ist daher ein basisches molybdänsaures Chromoxydkali.

Universität von Pennsylvanien, Juni 1894.

Bei der Redaktion eingegangen am 1. Juli 1894. 